\title{
Disability of Dialysis Patients and the Condition of Blood Vessels
}

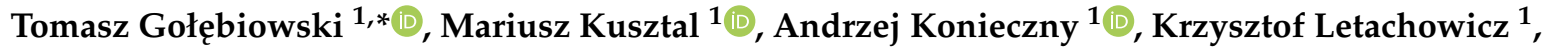 \\ Ada Gawryś ${ }^{1}$, Beata Skolimowska ${ }^{2}$, Bożena Ostrowska ${ }^{2}{ }^{\circledR}$, Sławomir Zmonarski ${ }^{1}$, \\ Dariusz Janczak $^{3}$ and Magdalena Krajewska ${ }^{1}$ (D)
}

1 Department of Nephrology and Transplantation Medicine, Wroclaw Medical University, 50-556 Wroclaw, Poland; mariusz.kusztal@umed.wroc.pl (M.K.); andrzej.konieczny@umed.wroc.pl (A.K.); krzysztof.letachowicz@umed.wroc.pl (K.L.); adagawrys@gmail.com (A.G.); slawomir.zmonarski@umed.wroc.pl (S.Z.); magdalena.krajewska@umed.wroc.pl (M.K.)

2 Department of Occupational Therapy, University School of Physical Education in Wroclaw, 51-612 Wroclaw, Poland; beata.skolimowska@awf.wroc.pl (B.S.); bozena.ostrowska@awf.wroc.pl (B.O.)

3 Department of Vascular, General and Transplantation Surgery, Wroclaw Medical University, 50-556 Wroclaw, Poland; dariusz.janczak@umed.wroc.pl

* Correspondence: tomasz.golebiowski@umed.wroc.pl

Received: 24 April 2020; Accepted: 8 June 2020; Published: 10 June 2020

\begin{abstract}
The number of elderly hemodialysis patients is constantly increasing worldwide. This population has a high burden of comorbid conditions, which impair daily activities. The aim of the study was to analyze problems of disability in hemodialysis patients in the context of cardiovascular (CV) complications and vascular condition. In this cross-sectional study, 129 patients (mean age 64.5) were enrolled. The degree of disability in Barthel index (Bi) and 10-year cardiovascular risk (QRISK ${ }^{\circledR} 3$ ) were assessed. A Mobil-O-Graph monitor was used for measuring hemodynamic parameters. Only $6.2 \%$ of patients were professionally active, $19 \%$ used a wheelchair for transport, and $16 \%$ used crutches. More than half $(51 \%)$ were independent in everyday activities reaching $80-100$ points on $\mathrm{Bi}$. The rest, with $\mathrm{Bi}<80$, were considered as dependent. The most common causes of disability were $\mathrm{CV}$ complications. The independent group (80-100 points) was characterized by significantly lower pulse wave velocity (PWV) and lower QRISK ${ }^{\circledR} 3$ compared to dependent patients. The degree of disability negatively correlated with age, $\mathrm{PWV}$, and $\mathrm{QRISK}{ }^{\circledR} 3$. Multivariate logistic regression revealed that disability $(\mathrm{Bi}<80)$ was independently associated with $\mathrm{CV}$ events in the past adjusted odds ratio (adj.OR) 4.83 (95\% confidence interval (95\% CI): 1.74-13.41) and higher PWV adj.OR 1.45 (95\% CI: 1.15-1.82). Our results indicate that CV diseases are the most important cause of functional impairment.
\end{abstract}

Keywords: hemodialysis; disability; end-stage renal disease; arterial stiffness; pulse wave velocity

\section{Introduction}

Patients aged 75 years or older represent the fastest growing segment of the subjects starting dialysis [1]. This population has a high burden of comorbid conditions, including cardiovascular (CV) diseases, which lead to disability and the need for continuous care resulting from problems in performing activities of daily living (ADLs). In this group, ADLs disability is strong and independent predictor of mortality [2]. The etiology of disability is multifactorial and may be divided into two groups, namely those associated with atherosclerosis and non-atherosclerotic diseases. In hemodialysis (HD) patients, atherosclerosis progresses much faster than in age-matched patients, with a normal glomerular filtration rate, and it is an important risk factor of cardiovascular (CV) events [3]. Heart failure, hemiplegia after 
stroke, or lower leg amputation are only examples of many arteriosclerotic consequences, which may limit the ability to perform daily self-care tasks. However, some data indicate that the musculoskeletal system involvement may significantly decrease the physical function of patients with end-stage renal disease [4]. In many cases, both CV diseases and disturbances of the musculoskeletal system may coexist, leading to extend functional disability (FD). In such circumstances, it is difficult to judge which illness has a more important impact on limiting daily activities. Additionally, disturbances and symptoms related to dialysis like sarcopenia, depression, cognitive impairment, visual impairment, and degenerative joints disease may aggravate or even be a leading reason for FD [5]. Pulse wave velocity (PWV) is generally regarded as surrogate to large/medium arterial stiffness and it is a common predictor of $\mathrm{CV}$ events in elderly on-dialysis patients. The association between disability due to $\mathrm{CV}$ diseases and PWV is not well studied. We hypothesized that the leading cause of functional impairment are cardiovascular complications, as a consequence of changes in vascular system.

The aim of the study was to analyze the problems of FD in HD patients in the context of cardiovascular complications and vascular condition.

\section{Material and Methods}

The potential participants were identified through a review of all patients undergoing hemodialysis who were recruited from two dialysis stations.

The inclusion criteria for hemodialysis patients were as follows: (1) age 18 years and over, (2) received regular dialysis for at least 6 months, and (3) were able to provide informed consent. The exclusion criteria included the following: (1) currently enrolled in another study or (2) receiving emergency in-patient care within four weeks. Written informed consent was received from each patient entering the study. Of the 139 eligible participants, 10 did not agree to take part in the study. Patients who were not recruited were similar in age and gender to those participating in the study.

One hundred twenty-nine patients (mean age 64.5, 54 females, with mean dialysis vintage 61 months) were enrolled in this cross-sectional study. Demographic and comorbidity data were collected from medical records and from a direct interview. This information allowed us to assess their degree of disability (Barthel index) and a 10-year cardiovascular risk (QRISK ${ }^{\circledR} 3$ online calculator).

Cardiovascular $(\mathrm{CV})$ diseases included diseases of the heart, vascular diseases of the brain, and diseases of blood vessels [6] particularly: myocardial infarction; heart failure New York Heart Association (NYHA) class > II, atrial fibrillation; implantable medical devices (IMD), i.e., cardio-stimulator or cardioverter-defibrillator; ischemic or hemorrhagic stroke; amputation due to extremity ischemia or diabetic foot; and surgery to repair an aortic aneurysm.

Coronary heart disease was defined as self-reported or on the basis of a history of myocardial infarction, coronary angioplasty, or bay-pass grafting. Stroke included a history of transient ischemic attack in the past or an ischemic/hemorrhagic event with neurological consequences. Peripheral arterial disease was defined as self-reported or medical report history of lower extremity angioplasty or significant vessel stenoses in imagine tests, amputation due to ischemia.

In most of patients (82 out of $129,63 \%$ ), two or more disorders were found, which may have a negative impact on performing ADLs. In such cases, an algorithm of choosing the leading disorder, responsible for disability, relies on determining which disorder was the most important in ADLs disability. Weakness associated with dialysis, as a leading disorder of disability, was found as self-reported when severely limiting the mobility and after excluding other potential factors of low muscle strength. Joint and skeletal system manifestation encompassed disorders typical for aging, i.e., degenerative joint diseases, but also disorders related to dialysis, such as following: Chronic Kidney Disease-Mineral and Bone Disorder (CKD-MBD), renal osteodystrophy due to secondary hyperparathyroidism, and dialysis-related amyloidosis.

The Barthel index is a 10-item instrument, measuring functional independence, in personal activities of daily living (ADLs) and the need for supervision or support. It is composed of 10 categories and includes the following items: feeding, bathing, grooming, dressing, bowel control, bladder control, 
toilet use, and transfers (bed to chair and back) $[7,8]$. The scale is a 100-point scale and is measured in increments of 5 points. The total score was 100 points. Subjects were categorized according to the Barthel index as follows: 80-100 points, independent including patients fully independent with 100 points; $60-79$ points, minimally dependent; $40-59$ points, partially dependent; $20-39$ points, highly dependent; and $<20$ points, fully dependent.

QRISK ${ }^{\circledR} 3$ score is an online tool evaluating a 10-year risk of cardiovascular accident and it was validated for different ethnicities and CKD patients [9]. It takes into account the following factors: age, ethnicity, diabetes, hypertension, smoking, angina or heart attack in a 1st degree relative $<60 \mathrm{y}$, atrial fibrillation, blood pressure treatment, blood pressure and chronic kidney disease, migraine, corticosteroids, systemic lupus erythematosus, atypical antipsychotics medication, severe mental illness, and erectile dysfunction. The results are presented as a risk of a heart attack or stroke within the next 10 years.

In addition, ambulatory measurements of hemodynamic parameters with Mobil-O-Graph monitor (Industrielle Entwicklung Medizintechnik und Vertriebsgesellschaft GmbH (IEM), Stolberg, Germany), which records oscillometric arm blood pressure: systolic and diastolic blood pressure (SBP and DBP), central systolic and diastolic blood pressure (cSBP and cDBP), pulse pressure (pPP), ejection fraction $(\mathrm{EF})$, cardiac output $(\mathrm{CO})$, and pulse waves. It calculates the augmentation index normalized to the heart rate (Aix@75) as a measure of wave reflections, and pulse wave velocity (PWV) as a measure of arterial stiffness. All tests were performed before the start of the one-day hemodialysis sessions.

Statistical analysis was performed using standard software (Statistica Version 13.3, (StatSoft, Tulsa, OK, USA)). Data for continuous variables were expressed as means and standard deviations. Paired independent sample $t$-test was used to compare the means of two continuous variables and the chi-square test for categorical variables. The relationship between two continuous variables was evaluated using the Pearson correlation. The unadjusted and adjusted multivariate Cox regression analysis was presented as an odds ratio (OR; 95\% confidence intervals (CI)). A $p$-value $<0.05$ was considered significant.

Ethics approval was granted by the Ethics Board of Wroclaw Medical University No KB 587/2018.

\section{Results}

The baseline demographic and blood chemistry characteristic are displayed in Table 1. Diabetes and renovascular disease were the most common causes of kidney failure, followed by others. Ischemic nephropathy was a more frequent cause of end-stage renal disease in dependent and glomerulonephritis dominate in group of independent patients (Table 2). In the study group of 129 patients (pts.), only $8(6.2 \%)$ were professionally active, $40(31 \%)$ received disability pension, and $81(62.8 \%)$ were retired. Twenty-five patients $(19 \%)$ used a wheelchair for transport and $21(16 \%)$ used crutches. More than half (51\%) were independent in everyday activities, reaching 80-100 points on the Barthel index; however, only $14 \%$ were fully independent (100 points). Minimally dependent (60-79 points) constituted $27 \%$ ( 35 pts) of all patients, partially dependent ( $40-59$ points) constituted $10 \%$ (13 pts), highly dependent ( $20-39$ points) constituted $7 \%$ ( $9 \mathrm{pts})$, and fully dependent ( $<20$ points) constituted $5 \%$ (6 pts). The most common causes of disability were heart problems, including heart failure in $20.9 \%$ of the patients, lower limb ischemia, diabetic foot, and amputation in $13.2 \%$, and cerebrovascular event in $10.9 \%$, followed by weakness associated with dialysis and degenerative joints disease. In the dependent group, cardiovascular diseases of heart, brain, and blood vessels as a leading cause of disability were more frequently observed in comparison to the independent group of patients. In contrary symptoms related to uremia (i.e., sarcopenia), weakness associated with dialysis was dominant in the independent subjects (Table 3). 
Table 1. Baseline characteristics of the groups: independent (80-100 points on the Barthel index) and dependent patients ( $<80$ points on the Barthel index).

\begin{tabular}{|c|c|c|c|c|c|}
\hline \multirow[b]{2}{*}{ Blood pressure and HR } & \multicolumn{2}{|c|}{ Independent $(n=67)$} & \multicolumn{2}{|c|}{ Dependent $(n=62)$} & \multirow[b]{2}{*}{$p$-value } \\
\hline & Mean & \pm & Mean & \pm & \\
\hline SBP (mmHg) & 142.8 & 26.3 & 139.7 & 29.9 & 0.530 \\
\hline $\mathrm{MBP}(\mathrm{mmHg})$ & 112.5 & 20.0 & 106.2 & 20.8 & 0.083 \\
\hline $\mathrm{DBP}(\mathrm{mmHg})$ & 86.9 & 17.0 & 77.8 & 15.7 & $<0.05$ \\
\hline $\mathrm{pPP}(\mathrm{mmHg})$ & 55.9 & 17.5 & 61.9 & 20.9 & 0.078 \\
\hline cSBP (mmHg) & 127.8 & 22.6 & 123.8 & 24.8 & 0.341 \\
\hline cDBP (mmHg) & 89.0 & 17.5 & 79.6 & 16.0 & $<0.05$ \\
\hline $\mathrm{cPP}(\mathrm{mmHg})$ & 38.7 & 12.7 & 44.2 & 15.2 & $<0.05$ \\
\hline HR (1/min.) & 73.5 & 14.3 & 72.1 & 11.6 & 0.541 \\
\hline \multicolumn{6}{|l|}{ Hemodynamic } \\
\hline $\mathrm{EF}(\mathrm{mL})$ & 72.9 & 14.9 & 73.3 & 14.4 & 0.898 \\
\hline $\mathrm{CO}(\mathrm{L} / \mathrm{min})$. & 5.3 & 1.1 & 5.2 & 1.1 & 0.869 \\
\hline $\operatorname{TVR}(\mathrm{s} \times \mathrm{mmHg} / \mathrm{mL})$ & 1.3 & 0.3 & 1.3 & 0.4 & 0.251 \\
\hline Cardiac index $\left(\mathrm{L} / \mathrm{min} . \times 1 / \mathrm{m}^{2}\right)$ & 2.9 & 0.7 & 2.9 & 0.8 & 0.677 \\
\hline \multicolumn{6}{|l|}{ Vascular stiffness } \\
\hline PWV (m/s) & 8.8 & 2.0 & 10.9 & 2.2 & $<0.05$ \\
\hline Aix@75 (\%) & 21.6 & 14.2 & 22.9 & 12.9 & 0.602 \\
\hline Augmentation pressure $(\mathrm{mmHg})$ & 10.0 & 8.4 & 12.6 & 9.6 & 0.102 \\
\hline Reflex $(\%)$ & 60.6 & 10.8 & 63.0 & 9.9 & 0.197 \\
\hline \multicolumn{6}{|l|}{ Sex, Age, and body size } \\
\hline Female. No. (\%) * & $28(41.8)$ & & $26(41.9)$ & & 0.992 \\
\hline Age $(y)$. & 57.9 & 14.7 & 71.6 & 12.5 & $<0.05$ \\
\hline $\mathrm{BMI}\left(\mathrm{m}^{2} / \mathrm{kg}^{2}\right)$ & 26.4 & 5.3 & 26.5 & 5.2 & 0.862 \\
\hline Weight (kg) & 75.4 & 19.2 & 73.1 & 16.0 & 0.458 \\
\hline \multicolumn{6}{|l|}{ Cardiovascular } \\
\hline QRISK $^{\circledR} 3(\%)$ & 22.6 & 13.0 & 32.9 & 11.8 & $<0.05$ \\
\hline History of CV events: No (\%) * & $30(45)$ & & $55(89)$ & & $<0.05$ \\
\hline \multicolumn{6}{|l|}{ Antihypertensive agents } \\
\hline$\beta$-blockers No $(\%) *$ & $50(74.6)$ & & $42(67.7)$ & & 0.723 \\
\hline CCB No $(\%) *$ & $46(68.7)$ & & $26(41.9)$ & & 0.102 \\
\hline ACEI/ABR No $(\%)$ * & $7(10.4)$ & & $5(8.0)$ & & 0.671 \\
\hline Diuretics No $(\%)$ * & $14(20.9)$ & & $15(24.2)$ & & 0.722 \\
\hline$\alpha$-blockers No $(\%) *$ & $20(29.9)$ & & $20(32.3)$ & & 0.830 \\
\hline
\end{tabular}

Abbreviations: SBP, systolic blood pressure; MBP, mean blood pressure; DBP, diastolic blood pressure; pPP, pulse pressure; $\mathrm{CSBP}$, central systolic blood pressure; $\mathrm{CDBP}$, central diastolic blood pressure; $\mathrm{cpPP}$, central pulse pressure; EF, ejection fraction; CO, cardiac output; TVR, total vascular resistance; PWV, pulse wave velocity; Aix@75, augmentation index normalized with 75/minute heart rate; BMI, body mass index; QRISK ${ }^{\circledR} 3$ score, 10 year risk of cardiovascular accident; CCB, calcium channel blocker; ACEI, angiotensin converting enzyme inhibitor; ARB, angiotensin receptor blocker; $\mathrm{HR}$, heart rate; $\mathrm{CV}$, cardiovascular; ${ }^{*}$ chi-square test.

Table 2. Causes of renal failure.

\begin{tabular}{ccccc}
\hline Cause of Renal Failure & $\begin{array}{c}\text { All Patients } \\
(\boldsymbol{n}=\mathbf{1 2 9})\end{array}$ & $\begin{array}{c}\text { Independent } \\
(\boldsymbol{n}=\mathbf{6 7})\end{array}$ & $\begin{array}{c}\text { Dependent } \\
(\boldsymbol{n}=\mathbf{6 2})\end{array}$ & $\boldsymbol{p}$-Value * \\
\hline Ischemic nephropathy/hypertension & $45(34.9)$ & $13(19.4)$ & $32(51.6)$ & $<0.01$ \\
No (\%) & $34(26.4)$ & $16(23.9)$ & $18(29.0)$ & 0.613 \\
Diabetic nephropathy No (\%) & $24(18.6)$ & $19(28.4)$ & $5(8.1)$ & $<0.05$ \\
Glomerulonephritis No (\%) & $8(6.2)$ & $6(9.0)$ & $2(3.2)$ & 0.205 \\
ADPKD No (\%) & $9(6.98)$ & $7(10.4)$ & $2(3.2)$ & 0.133 \\
Pyelonephritis (reflux, stones) No (\%) & $6(4.65)$ & $4(6.0)$ & $2(3.2)$ & 0.480 \\
Urologic cancer (kidney, prostate) No & $2(1.55)$ & $1(1.5)$ & $1(1.6)$ & 0.956 \\
(\%) & $1(0.78)$ & $1(1.5)$ & $0(0)$ & 0.337 \\
\hline Mnknown No (\%) &
\end{tabular}

Abbreviations: ADPKD, Autosomal dominant polycystic kidney disease. ${ }^{*}$ chi-square test between dependent and independent group. 
Table 3. Disorders leading to disability.

\begin{tabular}{ccccc}
\hline Disorders Leading to Disability & $\begin{array}{c}\text { All Patients } \\
(\boldsymbol{n}=\mathbf{1 2 9})\end{array}$ & $\begin{array}{c}\text { Independent } \\
(\boldsymbol{n}=\mathbf{6 7 )}\end{array}$ & $\begin{array}{c}\text { Dependent } \\
(\boldsymbol{n}=\mathbf{6 2})\end{array}$ & $\boldsymbol{p}$-Value * \\
\hline $\begin{array}{c}\text { Heart failure/coronary heart } \\
\text { disease/acquired valvular } \\
\text { heart disease }\end{array}$ & $27(20.9)$ & $3(4.5)$ & $24(38.7)$ & $<0.01$ \\
$\begin{array}{c}\text { Lower limb ischemia, diabetic foot } \\
\text { and amputation }\end{array}$ & $17(13.2)$ & $4(6.0)$ & $13(21.0)$ & $<0.05$ \\
$\begin{array}{c}\text { Central nervous system disorder } \\
\text { Sarcopenia/weakness associated }\end{array}$ & $14(10.9)$ & $3(4.5)$ & $11(17.7)$ & $<0.05$ \\
$\quad 28(21.7)$ & $26(38.8)$ & $2(3.2)$ & $<0.01$ \\
$\quad \begin{array}{c}\text { Join dialysis } \\
\text { and skeletal system }\end{array}$ & $18(14.0)$ & $9(13.4)$ & $9(14.5)$ & 0.878 \\
$\quad \begin{array}{l}\text { Vision and hearing loss } \\
\text { Respiratory tract disorders }\end{array}$ & $4(3.1)$ & $2(3.0)$ & $2(3.2)$ & 0.939 \\
$\quad 3(2.3)$ & $2(3.0)$ & $1(1.6)$ & 0.614 \\
\hline
\end{tabular}

* chi-square test between dependent and independent group.

The group of independent individuals (80-100 points on the Barthel index) was characterized by a significantly lower PWV, QRISK ${ }^{\circledR} 3$, and fewer CV events in the past compared to the dependent group (Table 1). In the group of independent patients, a few more patients received antihypertensive treatment ( $\beta$-blockers, $\alpha$-blockers, calcium channel blockers, angiotensin converting enzyme inhibitors, angiotensin receptor blockers were recorded) but the chi-square test did not show significant difference compared to the group of dependent patients $(p>0.05)$. The degree of disability according to Barthel index was negatively correlated with age, PWV, and QRISK ${ }^{\circledR} 3$ (Figure 1).

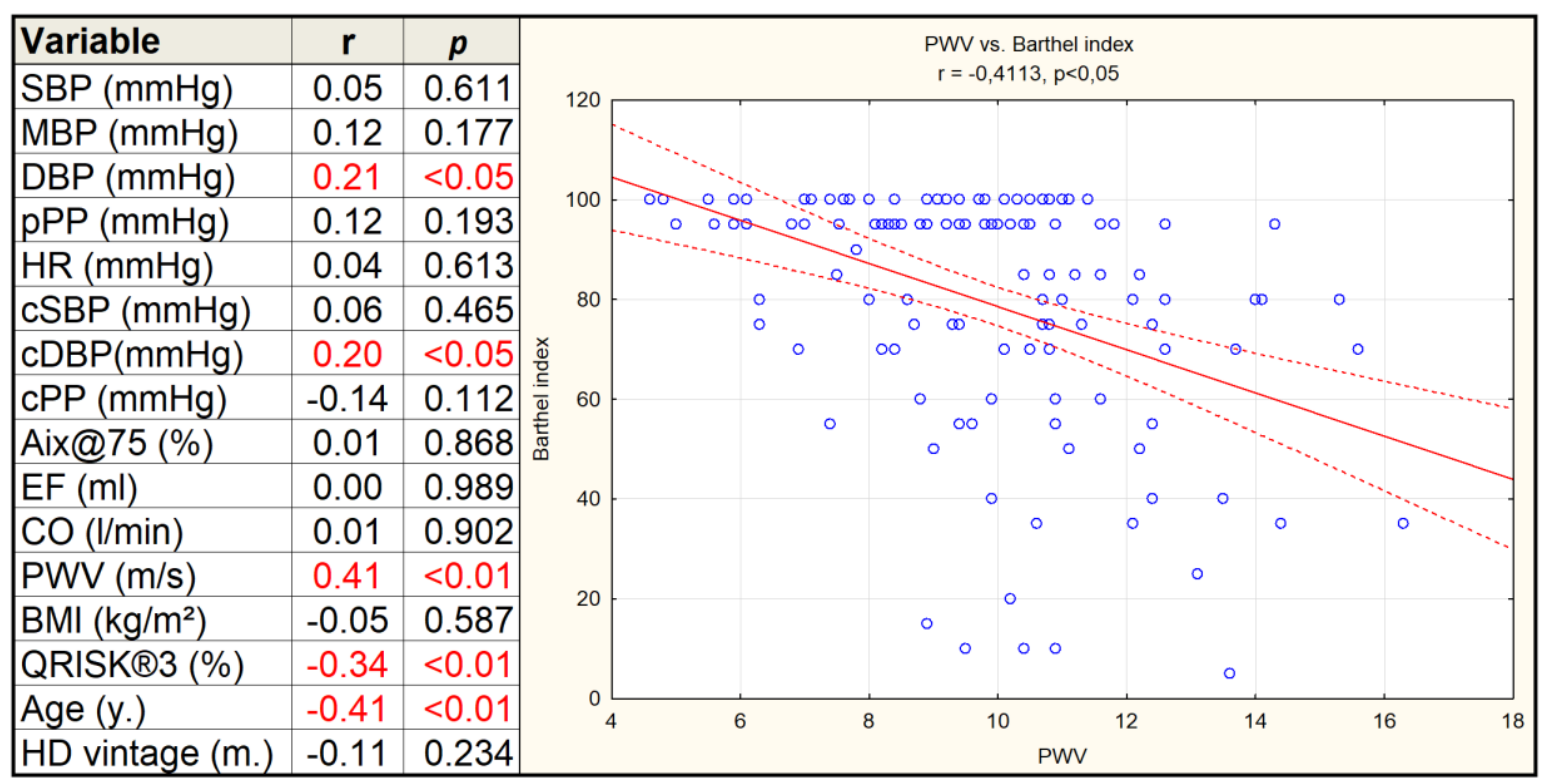

Figure 1. Correlations between Barthel index and other variables. r-index displayed in red for statistically significant correlations $p<0.05$. Abbreviations: SBP, systolic blood pressure; MBP, mean blood pressure; DBP, diastolic blood pressure; $\mathrm{pPP}$, pulse pressure; cSBP, central systolic blood pressure; cDBP, central diastolic blood pressure; cpPP, central pulse pressure; Aix@75, augmentation index normalized with 75/minute heart rate; EF, ejection fraction; $\mathrm{CO}$, cardiac output; $\mathrm{PWV}$, pulse wave velocity; BMI, body mass index; $\mathrm{QRISK}^{\circledR} 3,10$ year risk of cardiovascular accident; HD, hemodialysis.

Development and results of logistic regression model.

Crude odd ratios (ORs) for all predictors are shown in Table 4. The factors associated with having ADL disability (Barthel index $<80$ points) included cardiovascular events in the past, higher QRISK $^{\circledR} 3$, 
age, higher PWW, lower diastolic pressure (DBP and cDBP), higher central pulse pressure (cpPP). No significant relationship with disability was observed for Aix@75, BMI, dialysis vintage SBP and $\mathrm{MBP}$, and parameters of heart function (EF, CO).

Table 4. Univariate logistic regression. Variables correlated to dependent status (Barthel index $<80$ points).

\begin{tabular}{cccccc}
\hline Variable & Estimate & OR & & $\mathbf{9 5 \%}$ CI & $p$-Value \\
\hline Age (year.) & 0.075 & 1.08 & 1.04 & 1.11 & $<0.05$ \\
PWV (m/s) & 0.499 & 1.65 & 1.33 & 2.04 & $<0.05$ \\
Aix@75 (\%) & 0.007 & 1.01 & 0.98 & 1.03 & 0.60 \\
BMI (kg/m $\left.{ }^{2}\right)$ & 0.006 & 1.01 & 0.94 & 1.08 & 0.86 \\
QRISK $3(\%)$ & 0.066 & 1.07 & 1.04 & 1.10 & $<0.05$ \\
HD (m) & 0.004 & 1.00 & 1.00 & 1.01 & 0.15 \\
SBP (mmHg) & -0.004 & 1.00 & 0.98 & 1.01 & 0.53 \\
MBP (mmHg) & -0.015 & 0.98 & 0.97 & 1.00 & 0.09 \\
DBP (mmHg) & -0.034 & 0.97 & 0.94 & 0.99 & $<0.05$ \\
pPP (mmHg) & 0.017 & 1.02 & 1.00 & 1.04 & 0.08 \\
HR (1/min) & -0.008 & 0.99 & 0.97 & 1.02 & 0.54 \\
cSBP (mmHg) & -0.007 & 0.99 & 0.98 & 1.01 & 0.34 \\
cDBP (mmHg) & -0.034 & 0.97 & 0.95 & 0.99 & $<0.05$ \\
cpPP (mmHg) & 0.029 & 1.03 & 1.00 & 1.06 & $<0.05$ \\
EF (mL) & 0.002 & 1.00 & 0.98 & 1.03 & 0.90 \\
CO (mL/min.) & -0.003 & 1.00 & 0.97 & 1.03 & 0.87 \\
History of CV $(1)$ & 2.271 & 9.69 & 3.85 & 24.37 & $<0.05$ \\
\hline
\end{tabular}

Abbreviations: OR, odds ratio; $\mathrm{CI}$, confidence interval.

Based on a correlation analysis between each predictor, the groups of strongly associated predictors were extracted and finally one representative was chosen to avoid collinearity. All the remaining predictors were entered into a multivariable logistic regression model to obtain adjusted estimates. $\mathrm{CV}$ events in the past and higher PWV were the strongest, independent predictors for ADL disability with adjusted ORs 4.83 (95\% CI: 1.74-13.41) and OR 1.45 (95\% CI: 1.15-1.82), respectively (Table 5).

Table 5. Multivariate logistic regression.

\begin{tabular}{cccccc}
\hline Variable & Estimate & adj.OR * & \multicolumn{2}{c}{$\mathbf{9 5 \% \text { CI }}$} & $p$-Value \\
\hline History of CV $(1)$ & 1.576 & 4.83 & 1.74 & 13.41 & $<0.05$ \\
PWV (m/s) & 0.370 & 1.45 & 1.15 & 1.82 & $<0.05$ \\
CDBP $(\mathrm{mmHg})$ & -0.031 & 0.97 & 0.94 & 0.99 & $<0.05$ \\
\hline
\end{tabular}

Abbreviations: adj.OR, adjusted odds ratio. * correlated to Age (year), Aix@75, QRISK ${ }^{\circledR}$ 3, MBP, cpPP.

\section{Discussion}

Disability is defined as difficulty or dependency in carrying out activities that are essential to independent living. The Barthel index encompasses 10 activities of daily living (ADLs): feeding, bathing, grooming, dressing, using a toilet, bowels and bladder incontinence, transfers, mobility, and use of stairs. The inability to perform such activities engages family members or other informal caregivers. In addition, ADLs disability may strongly predict morbidity, mortality, and hospitalization in dialysis adult [10].

The results of our recent study reflect three important findings regarding ADLs disability. The first was that disability is common in the end-stage renal disease (ESRD) population. Half of the studied population ( $48 \%$ of patients) was functionally dependent and their Barthel index was lower than $<80$ points, which means that they need support in at least one ADL. Previous studies reported the approximate rates of functional impairment in ADLs (29-52\%) [11,12]. The prevalence of disability among patients with chronic kidney disease (CKD), not receiving dialysis, accounts for $18-24 \%$ of 
elderly patients over 65 years. In Kavanaghetet al.'s study, even $58.8 \%$ of the participants demonstrated dependence in at least one ADL or instrumental activities of daily livings (IADLs) [13]. Consistent results were reported by Cook et al., who recruited 162 patients aged 65 and older (mean age was 75 years). In this cohort, $52 \%$ of subjects were dependent both in ADLs and IADLs [14]. These differences may be explained by the different age of the study population. Only $14 \%$ of the studied dialysis population had no functional impairment of any type. The approximately similar percentage (5\%) was observed in the aforementioned study conducted by Cook et al. [14]. Characteristics of disabled patients overlap with the frailty status, which is defined as the presence of three or more, out of five, of following criteria: unintentional weight loss, weakness, self-reported fatigue, slow walking speed, and low physical activity level. Frailty status is a well-known CV risk factor in ESRD and in the non-renal population $[15,16]$.

The second discovery was that cardiovascular (CV) complications are the leading cause of disability. The history of CV event was observed in $66 \%$ of study subjects and more frequently in the group of dependent patients ( $89 \%$ vs. $45 \%$; Table 1$)$. CV events in the past were also the strongest predictor of functional disability (FD), increasing the risk of disability almost five times (Table 5). Heart failure as a complication of coronary heart disease was the most frequent cause of FD (in 20.9\% of pts.), followed by other complications associated with arteriosclerosis, i.e., peripheral arteries in the lower extremity (including amputation) and stroke (Table 3). Data from other authors confirm that CV diseases are the main cause of death both in community-dwelling elderly and patients with reduced kidney function, but coronary artery disease and stroke are the two most important causes of death [15,17].

The third important finding, derived from our study, was that there is a significant association between vascular changes, expressed by arterial stiffness, and the degree of ADL disability in the Barthel index (Bi). The group of dependent patients is characterized by significantly increased arterial stiffness expressed by pulse wave velocity (PWV; Table 1). Lower disability score (Bi) was associated with higher PWV, which was an independent predictor for dependency status, with an increase in adjusted odds ratio (adj.OR) 1.4 pro $1 \mathrm{~m} / \mathrm{s}$ of PWV. In addition, we found lower diastolic blood pressure and higher central pulse pressure in the group of dependent patients (Table 1). This is in line with higher PWV score, a well-known surrogate of large arterial stiffness, and strongly suggests higher arterial stiffness. To our knowledge, it is the first study evaluating the relationship between PWV and disability score. The mechanism underlining arterial stiffness in the CKD population is complex and can be attributed to the progression of vascular calcification, owing to Chronic Kidney Disease-Mineral and Bone Disorder (CKD-MBD) and an imbalance between factors promoting calcification i.e., phosphate, parathormone, fibroblast growth factor-23 (FGF-23), and calcification inhibitors (e.g., fetuin-A) [18]. Faster progression of increased aortic PWV can be found more often in the CKD population than among individuals with normal kidney function [19]. A meta-analysis of prospective observational data confirms that PWV was a significant predictor of coronary heart disease, stroke, and cardiovascular events, with hazard ratios of 1.23, 1.28, and 1.30, respectively [20]. Regardless, PWV is a useful, non-invasive, diagnostic and prognostic tool for the prediction of cardiovascular disease in the CKD population; however as a mortality predictor, it may not necessary show superior usefulness comparing to other validated clinical risk scores. Recent comparison of PWV vs. annualized rate of occurrence (ARO) risk score in patients with ESRD indicate that PWV has inferior prognostic power for all-cause and cardiovascular mortality compared to ARO risk score [21,22]. Additional data point that 24-h PWV may have a higher prediction value than PWV in the office setting for all-cause-mortality in hemodialysis patients [23]. The 2018 European Society of Cardiology Guidelines determine the PWV threshold of $10 \mathrm{~m} / \mathrm{s}$ as suggestive of increased cardiovascular risk and is appropriate to be utilized to stratify intermediate risk patients (Grade 2b recommendation) [24]. Aortic PWV was also broadly used in interventional studies $[25,26]$.

Data from the Dialysis Outcomes and Practice Patterns Study (DOPPS study) confirm that there is an independent relationship between functional impairment and adverse health outcomes [27]. The accumulation of conventional and unconventional risk factors, typical for CKD patients, initiate the 
pathological chain process, which includes the following elements: increased arterial stiffness, hypertension, left ventricular heart hypertrophy, arteriosclerosis with cardiovascular complications, including vascular bed in the brain, heart and peripheral arteries. The final element is disability or death. Owing to non-traditional risk factors (including biochemical abnormalities of hyperphosphatemia and hyperparathyroidism, renal osteodystrophy, and vascular calcification), the risk of in-hospital FD progression after CV event is higher in dialysis than in non-dialysis patients [28]. This pathway links functional dependence with changes in the vascular system and seems to be crucial in the dialysis population.

Naturally, cardiovascular diseases are not a separate culprit of impaired functioning. In $22 \%$ and $14 \%$ of participants, fatigue/weakness associated with dialysis and skeletal system manifestations were the leading cause of FD, respectively. This issue should be discussed in connection, as both include non-atherosclerosis disorders frequently limiting functional independence. Sarcopenia is a common disturbance in the dialysis population and is associated with physical disability and mortality $[29,30]$. The etiology is multifactorial, although a sedentary lifestyle is regarded as the most important factor of low physical fitness [31]. In addition, many other factors may contribute to this disturbance: anemia, the uremic milieu itself, inflammatory state, and malnutrition [32,33]. General weakness was noted in $60 \%$ of patients with secondary hyperparathyroidism prepared to undergo a parathyroidectomy [34]. In the Dialysis Morbidity and Mortality Study (DMMS), out of 2275 dialysis patients, $66 \%$ were described as weak and fragile [35] in comparison the group of people over 65 years of age, without kidney disease, this trait was found in $6.9 \%$ [36] to $16.3 \%$ [37]. Renal osteodystrophy (ROD) is common in CKD and two types are encountered: high turnover and low turnover disease. The prevalence of high turnover bone disease (osteitis fibrosa cystica) among dialysis patients has markedly decreased [38,39]. The symptomatology of these two different disorders includes changes in bones, joints, and the vessels. In a study by Afifi et al., musculoskeletal manifestations of ROD were frequently observed in the dialysis population. Arthralgia was present in $83 \%$ of the subjects, subperiosteal resorption of the terminal phalanges and achilles tendinopathy in $67.9 \%$. These abnormalities corresponded with a low self-report functional disability index, as shown in the health assessment questionnaire (HAQ-DI) [4].

In our analysis, the duration of renal replacement therapy has no impact on functional impairment. Due to the cross-sectional character of the study, this finding should be regarded with caution, as from clinical practice functional decline is usually observed in most patients after years of dialysis. In a large study from Taiwan, using the Barthel index for a longitudinal evaluation of functional dependence, in follow-up time of 13 years, the authors found that patients who started dialysis at an age above 35 years experienced approximately 3 years of disability; however, with age increases the proportion of functional disabilities and care needs [40]. It should be also noted that FD in elderly patients is exacerbated and frequently observed after the initiation of hemodialysis treatment [41].

Identification of a functional decline in the HD population may be clinically important, because early intervention may diminish the degree of disability. Some evidence suggests that multidisciplinary rehabilitation programs may improve the ability to perform different tasks of daily living. These programs should encompass counselling with a specialized team, including a physiotherapist, psychiatrist, behavioral specialist, geriatrist, or others when appropriate. Individualized, supervised, or grouped exercise training may significantly improve muscle strength and performing ADLs even in low functioning patients [42,43]. Some limited evidence studies suggest that exercise is a potential strategy to improve the vascular condition and lower blood pressure in CKD [44]. Increasing physical activity levels should be a major goal at all levels of health care [45]. Exercise is hypothesized to minimize overall cardiovascular risk and potentially mitigates the impact of hypertension on arterial stiffness. One cross-over study of 19 patients showed a trend towards improvement in PWV in patients who undertook interdialytic exercise, with subsequent deterioration in PWV after cessation of exercise [46], but another study has failed to demonstrate that exercise has any significant impact on PWV [47]. 
A few limitations should be underlined when assessing our findings. Precise data indicate that except stiffness of large and small arteries, many factors may influence hemodynamic parameters of pulse wave analysis including cardiac output, existence of arteriovenous fistula, and hydration status of the individual patients [48]. Owing to the cross-sectional study design, we were unable to comment on the dynamic nature of disability over time. There might be a subjective element in the assessment of the main cause of disability, because in a significant number of patients two or more disturbances, diseases, or symptoms coexisted and only most the important one was chosen. Sarcopenia or weakness associated with dialysis may be confused with depression or sleep disturbances, as they all appear as fatigue. Our data are also limited by the fact that we recruited dialysis patients from only two in-center HD units.

\section{Conclusions}

To our knowledge, this is first study evaluating functional disability (FD) in hemodialysis (HD) patients in the context of vascular conditions. Our results indicate that half of HD patients show some degree of FD, with considerable consequences on their autonomy. Functional independence in the $\mathrm{HD}$ population appears to be the exception rather than the rule. Cardiovascular (CV) events are the most important cause of functional decline. The group of patients with a higher degree of disability is usually older and characterized by a high burden of CV complications. Additionally, more advanced changes in the arteries might be the reason for the higher risk of $\mathrm{CV}$ incidents in the future.

Author Contributions: Conceptualization, T.G., M.K. (Mariusz Kusztal), A.K., A.G., S.Z., B.O., B.S., D.J., and M.K. (Magdalena Krajewska); Data curation, T.G., A.K., K.L., A.G., S.Z., B.O., and B.S.; Formal analysis, T.G. and M.K. (Mariusz Kusztal); Funding acquisition, T.G.; Investigation, T.G., M.K. (Mariusz Kusztal), A.K., K.L., A.G., S.Z., and B.S.; Methodology, T.G., M.K. (Mariusz Kusztal), A.K., K.L., D.J., and M.K. (Magdalena Krajewska); Project administration, T.G. and M.K. (Magdalena Krajewska); Resources, M.K. (Mariusz Kusztal), B.O., B.S., D.J., and M.K. (Magdalena Krajewska); Supervision, T.G., D.J., and M.K. (Magdalena Krajewska); Visualization, T.G., A.K., K.L., S.Z., B.O., and M.K. (Magdalena Krajewska); Writing-original draft, T.G. and A.K.; Writing-review and editing, M.K. (Mariusz Kusztal), K.L., A.G., A.Z., B.O., B.S., D.J., and M.K. (Magdalena Krajewska). All authors have read and agreed to the published version of the manuscript.

Funding: The study is supported by the Wroclaw Medical University statutory funds (SUB.C160.19.055). It was an investigator-initiated research. The funding body had no role in the study design, data collection, analyses, and interpretation, or in writing the manuscript.

Conflicts of Interest: The authors declare no conflict of interest.

\section{References}

1. United States Renal Data System. 2018 USRDS Annual Data Report: Epidemiology of Kidney Disease in the United States; National Institutes of Health, National Institute of Diabetes and Digestive and Kidney Diseases: Bethesda, MD, USA, 2018.

2. McAdams-Demarco, M.A.; Law, A.; Garonzik-Wang, J.M.; Gimenez, L.; Jaar, B.G.; Walston, J.D.; Segev, D.L. Activity of daily living disability and dialysis mortality: Better prediction using metrics of aging. J. Am. Geriatr. Soc. 2012, 60, 1981-1982. [CrossRef] [PubMed]

3. Levey, A.S.; de Jong, P.E.; Coresh, J.; El Nahas, M.; Astor, B.C.; Matsushita, K.; Gansevoort, R.T.; Kasiske, B.L.; Eckardt, K.U. The definition, classification, and prognosis of chronic kidney disease: A KDIGO Controversies Conference report. Kidney Int. 2011, 80, 17-28. [CrossRef] [PubMed]

4. Afifi, W.M.; Abo Elsaoud, A.M.; Elgawish, M.H.; Ghorab, A.M. Musculoskeletal manifestations in end-stage renal disease patients on hemodialysis and relation to parathyroid dysfunction. Saudi J. Kidney Dis.Transpl. 2019, 30, 68-82. [CrossRef] [PubMed]

5. Farragher, J.; Jassal, S.V. Rehabilitation of the geriatric dialysis patient. Semin. Dial. 2012, 25, 649-656. [CrossRef] [PubMed]

6. Thomas, H.; Diamond, J.; Vieco, A.; Chaudhuri, S.; Shinnar, E.; Cromer, S.; Perel, P.; Mensah, G.A.; Narula, J.; Johnson, C.O.; et al. Global Atlas of Cardiovascular Disease 2000-2016: The path to prevention and control. Glob. Heart 2018, 13, 143-163. [CrossRef] [PubMed] 
7. Mahoney, F.I.; Barthel, D.W. Functional evaluation: The Barthel Index. Md. State Med. J. 1965, 14, 61-65. [PubMed]

8. Wade, D.T.; Collin, C. The Barthel ADL Index: A standard measure of physical disability? Int.Disabil. Stud. 1988, 10, 64-67. [CrossRef] [PubMed]

9. Hippisley-Cox, J.; Coupland, C.; Brindle, P. Development and validation of QRISK3 risk prediction algorithms to estimate future risk of cardiovascular disease: Prospective cohort study. BMJ 2017, 357, j2099. [CrossRef] [PubMed]

10. Bossola, M.; Marino, C.; Di Napoli, A.; Agabiti, N.; Tazza, L.; Davoli, M.; Dialysis and Transplant Lazio Region Registry Scientific Committee. Functional impairment and risk of mortality in patients on chronic hemodialysis: Results of the Lazio Dialysis Registry. J. Nephrol. 2018, 31, 593-602. [CrossRef] [PubMed]

11. Goto, N.A.; van Loon, I.N.; Morpey, M.I.; Verhaar, M.C.; Willems, H.C.; Emmelot-Vonk, M.H.; Bots, M.L.; Boereboom, F.T.J.; Hamaker, M.E. Geriatric assessment in elderly patients with end-stage kidney disease. Nephron 2019, 141, 41-48. [CrossRef] [PubMed]

12. Abdulan, I.M.; Onofriescu, M.; Stefaniu, R.; Mastaleru, A.; Mocanu, V.; Alexa, I.D.; Covic, A. The predictive value of malnutrition for functional and cognitive status in elderly hemodialysis patients. Int. Urol. Nephrol. 2019, 51, 155-162. [CrossRef] [PubMed]

13. Kavanagh, N.T.; Schiller, B.; Saxena, A.B.; Thomas, I.C.; Kurella Tamura, M. Prevalence and correlates of functional dependence among maintenance dialysis patients. Hemodial. Int. 2015, 19, 593-600. [CrossRef] [PubMed]

14. Cook, W.L.; Jassal, S.V. Functional dependencies among the elderly on hemodialysis. Kidney Int. 2008, 73, 1289-1295. [CrossRef] [PubMed]

15. Ricci, N.A.; Pessoa, G.S.; Ferriolli, E.; Dias, R.C.; Perracini, M.R. Frailty and cardiovascular risk in community-dwelling elderly: A population-based study. Clin. Interv. Aging 2014, 9, 1677-1685. [CrossRef] [PubMed]

16. Stack, A.G.; Molony, D.A.; Rives, T.; Tyson, J.; Murthy, B.V. Association of physical activity with mortality in the US dialysis population. Am. J. Kidney Dis. 2005, 45, 690-701. [CrossRef] [PubMed]

17. Thompson, S.; James, M.; Wiebe, N.; Hemmelgarn, B.; Manns, B.; Klarenbach, S.; Tonelli, M. Cause of death in patients with reduced kidney function. J. Am. Soc. Nephrol. 2015, 26, 2504-2511. [CrossRef] [PubMed]

18. Krishnasamy, R.; Tan, S.J.; Hawley, C.M.; Johnson, D.W.; Stanton, T.; Lee, K.; Mudge, D.W.; Campbell, S.; Elder, G.J.; Toussaint, N.D.; et al. Progression of arterial stiffness is associated with changes in bone mineral markers in advanced CKD. BMC Nephrol. 2017, 18, 281. [CrossRef] [PubMed]

19. Temmar, M.; Liabeuf, S.; Renard, C.; Czernichow, S.; Esper, N.E.; Shahapuni, I.; Presne, C.; Makdassi, R.; Andrejak, M.; Tribouilloy, C.; et al. Pulse wave velocity and vascular calcification at different stages of chronic kidney disease. J. Hypertens. 2010, 28, 163-169. [CrossRef] [PubMed]

20. Ben-Shlomo, Y.; Spears, M.; Boustred, C.; May, M.; Anderson, S.G.; Benjamin, E.J.; Boutouyrie, P.; Cameron, J.; Chen, C.H.; Cruickshank, J.K.; et al. Aortic pulse wave velocity improves cardiovascular event prediction: An individual participant meta-analysis of prospective observational data from 17,635 subjects. J. Am. Coll. Cardiol. 2014, 63, 636-646. [CrossRef]

21. Tripepi, G.; Agharazii, M.; Pannier, B.; D’Arrig o, G.; Mallamaci, F.; Zoccali, C.; London, G. Pulse wave velocity and prognosis in end-stage kidney disease. Hypertension 2018, 71, 1126-1132. [CrossRef] [PubMed]

22. Anker, S.D.; Gillespie, I.A.; Eckardt, K.U.; Kronenberg, F.; Richards, S.; Drueke, T.B.; Stenvinkel, P.; Pisoni, R.L.; Robinson, B.M.; Marcelli, D.; et al. Development and validation of cardiovascular risk scores for haemodialysis patients. Int. J. Cardiol. 2016, 216, 68-77. [CrossRef] [PubMed]

23. Matschkal, J.; Mayer, C.C.; Sarafidis, P.A.; Lorenz, G.; Braunisch, M.C.; Guenthner, R.; Angermann, S.; Steubl, D.; Kemmner, S.; Bachmann, Q.; et al. Comparison of 24-h and office pulse wave velocity for prediction of mortality in hemodialysis patients. Am. J. Nephrol. 2019, 49, 317-327. [CrossRef] [PubMed]

24. Williams, B.; Mancia, G.; Spiering, W.; AgabitiRosei, E.; Azizi, M.; Burnier, M.; Clement, D.L.; Coca, A.; de Simone, G.; Dominiczak, A.; et al. 2018 ESC/ESH Guidelines for the management of arterial hypertension. Eur. Heart J. 2018, 39, 3021-3104. [CrossRef] [PubMed]

25. Boesby, L.; Elung-Jensen, T.; Strandgaard, S.; Kamper, A.L. Eplerenone attenuates pulse wave reflection in chronic kidney disease stage 3-4-A randomized controlled study. PLoS ONE 2013, 8, e64549. [CrossRef] [PubMed] 
26. Fassett, R.G.; Robertson, I.K.; Ball, M.J.; Geraghty, D.P.; Sharman, J.E.; Coombes, J.S. Effects of atorvastatin on arterial stiffness in chronic kidney disease: A randomised controlled trial. J. Atheroscler. Thromb. 2010, 17, 235-241. [CrossRef] [PubMed]

27. Jassal, S.V.; Karaboyas, A.; Comment, L.A.; Bieber, B.A.; Morgenstern, H.; Sen, A.; Gillespie, B.W.; De Sequera, P.; Marshall, M.R.; Fukuhara, S.; et al. Functional dependence and mortality in the international dialysis outcomes and practice patterns study (DOPPS). Am. J. Kidney Dis. 2016, 67, 283-292. [CrossRef] [PubMed]

28. Usui, T.; Hanafusa, N.; Yasunaga, H.; Nangaku, M. Association of dialysis with in-hospital disability progression and mortality in community-onset stroke. Nephrology 2019, 24, 737-743. [CrossRef] [PubMed]

29. Isoyama, N.; Qureshi, A.R.; Avesani, C.M.; Lindholm, B.; Barany, P.; Heimburger, O.; Cederholm, T.; Stenvinkel, P.; Carrero, J.J. Comparative associations of muscle mass and muscle strength with mortality in dialysis patients. Clin. J. Am. Soc. Nephrol. 2014, 9, 1720-1728. [CrossRef] [PubMed]

30. Matsuzawa, R.; Roshanravan, B.; Shimoda, T.; Mamorita, N.; Yoneki, K.; Harada, M.; Watanabe, T.; Yoshida, A.; Takeuchi, Y.; Matsunaga, A. Physical activity dose for hemodialysis patients: Where to begin? Results from a prospective cohort study. J. Ren. Nutr. 2018, 28, 45-53. [CrossRef] [PubMed]

31. O'Hare, A.M.; Tawney, K.; Bacchetti, P.; Johansen, K.L. Decreased survival among sedentary patients undergoing dialysis: Results from the dialysis morbidity and mortality study wave 2. Am. J. Kidney Dis. 2003, 41, 447-454. [CrossRef] [PubMed]

32. Beusterien, K.M.; Nissenson, A.R.; Port, F.K.; Kelly, M.; Steinwald, B.; Ware, J.E., Jr. The effects of recombinant human erythropoietin on functional health and well-being in chronic dialysis patients. J. Am. Soc. Nephrol. 1996, 7, 763-773. [PubMed]

33. Moore, G.E.; Parsons, D.B.; Stray-Gundersen, J.; Painter, P.L.; Brinker, K.R.; Mitchell, J.H. Uremic myopathy limits aerobic capacity in hemodialysis patients. Am. J. Kidney Dis. 1993, 22, 277-287. [CrossRef]

34. Chou, F.F.; Lee, C.H.; Chen, J.B. General weakness as an indication for parathyroid surgery in patients with secondary hyperparathyroidism. Arch. Surg. 1999, 134, 1108-1111. [CrossRef] [PubMed]

35. United States Renal Data System. The USRDS dialysis morbidity and mortality study: Wave 2. United States renal data system. Am. J. Kidney Dis. 1997, 30, S67-S85. [CrossRef]

36. Fried, L.P.; Tangen, C.M.; Walston, J.; Newman, A.B.; Hirsch, C.; Gottdiener, J.; Seeman, T.; Tracy, R.; Kop, W.J.; Burke, G.; et al. Frailty in older adults: Evidence for a phenotype. J. Gerontol. A Biol. Sci. Med. Sci. 2001, 56, M146-M156. [CrossRef] [PubMed]

37. Wuerth, D.; Finkelstein, S.H.; Finkelstein, F.O. The identification and treatment of depression in patients maintained on dialysis. Semin. Dial. 2005, 18, 142-146. [CrossRef] [PubMed]

38. Malluche, H.H.; Mawad, H.W.; Monier-Faugere, M.C. Renal osteodystrophy in the first decade of the new millennium: Analysis of 630 bone biopsies in black and white patients. J. Bone Miner. Res. 2011, 26, 1368-1376. [CrossRef] [PubMed]

39. Barreto, F.C.; Barreto, D.V.; Moyses, R.M.; Neves, K.R.; Canziani, M.E.; Draibe, S.A.; Jorgetti, V.; Carvalho, A.B. K/DOQI-recommended intact PTH levels do not prevent low-turnover bone disease in hemodialysis patients. Kidney Int. 2008, 73, 771-777. [CrossRef] [PubMed]

40. Hung, M.C.; Sung, J.M.; Chang, Y.T.; Hwang, J.S.; Wang, J.D. Estimation of physical functional disabilities and long-term care needs for patients under maintenance hemodialysis. Med. Care 2014, 52, 63-70. [CrossRef] [PubMed]

41. Kurella Tamura, M.; Covinsky, K.E.; Chertow, G.M.; Yaffe, K.; Landefeld, C.S.; McCulloch, C.E. Functional status of elderly adults before and after initiation of dialysis. N. Engl. J. Med. 2009, 361, 1539-1547. [CrossRef] [PubMed]

42. Nonoyama, M.L.; Brooks, D.; Ponikvar, A.; Jassal, S.V.; Kontos, P.; Devins, G.M.; Spanjevic, L.; Heck, C.; Laprade, J.; Naglie, G. Exercise program to enhance physical performance and quality of life of older hemodialysis patients: A feasibility study. Int. Urol. Nephrol. 2010, 42, 1125-1130. [CrossRef] [PubMed]

43. Golebiowski, T.; Kusztal, M.; Weyde, W.; Dziubek, W.; Wozniewski, M.; Madziarska, K.; Krajewska, M.; Letachowicz, K.; Strempska, B.; Klinger, M. A program of physical rehabilitation during hemodialysis sessions improves the fitness of dialysis patients. Kidney Blood Press. Res. 2012, 35, 290-296. [CrossRef] [PubMed] 
44. Thompson, S.; Wiebe, N.; Padwal, R.S.; Gyenes, G.; Headley, S.A.E.; Radhakrishnan, J.; Graham, M. The effect of exercise on blood pressure in chronic kidney disease: A systematic review and meta-analysis of randomized controlled trials. PLoS ONE 2019, 14, e0211032. [CrossRef] [PubMed]

45. Sharman, J.E.; La Gerche, A.; Coombes, J.S. Exercise and cardiovascular risk in patients with hypertension. Am. J. Hypertens. 2015, 28, 147-158. [CrossRef] [PubMed]

46. Toussaint, N.D.; Polkinghorne, K.R.; Kerr, P.G. Impact of intradialytic exercise on arterial compliance and B-type natriuretic peptide levels in hemodialysis patients. Hemodial. Int. 2008, 12, 254-263. [CrossRef] [PubMed]

47. Chan, D.; Green, S.; Fiatarone Singh, M.A.; Barnard, R.; Bonder, C.S.; Cheema, B.S. Effect of intradialytic resistance training on pulse wave velocity and associated cardiovascular disease biomarkers in end stage renal disease. Nephrology 2018, 23, 1055-1062. [CrossRef] [PubMed]

48. Debowska, M.; Poleszczuk, J.; Dabrowski, W.; Wojcik-Zaluska, A.; Zaluska, W.; Waniewski, J. Impact of hemodialysis on cardiovascular system assessed by pulse wave analysis. PLoS ONE 2018, 13, e0206446. [CrossRef] [PubMed]

(C) 2020 by the authors. Licensee MDPI, Basel, Switzerland. This article is an open access article distributed under the terms and conditions of the Creative Commons Attribution (CC BY) license (http://creativecommons.org/licenses/by/4.0/). 